\title{
Microbiological and molecular investigation of an increase of human listeriosis in Belgium, 2006-2007
}

M Yde (marc.yde@iph.fgov.be) ${ }^{1}$, N Botteldoorn ${ }^{1}$, S Bertrand $^{1}$, J M Collard ${ }^{1}$, K Dierick $^{1}$

1. Scientific Institute of Public Health, Section of Bacteriology, Brussels, Belgium

Citation style for this article:

Citation style for this article: Yde M, Botteldoorn N, Bertrand S, Collard JM, Dierick K. Microbiological and molecular investigation of an increase of human

listeriosis in Belgium, 2006-2007. Euro Surveill. 2010;15(6):pii=19482. Available online: http://www.eurosurveillance.org/ViewArticle.aspx?Articleld=19482

This article has been published on 11 February 2010

In Belgium, the majority of cases of listeriosis are sporadic cases. In this study we present evidence for an episode of listeriosis: a time-linked cluster of cases that occurred in 2006 and 2007, and the identification of identical strains. The episode involved 11 patients, infected with Listeria monocytogenes of serovar $4 \mathrm{~b}$. The source of infection was not detected.

\section{Introduction}

Listeria monocytogenes is a gram-positive intracellular food-borne pathogen. In some groups (immunosuppressed people, neonates, pregnant women and their unborn children) it can be an important cause of lifethreatening bacteraemia and meningitis. Because listeriosis has a long incubation time (three to 60 days), it is often difficult to trace the source of infection. This explains why the vast majority of cases are notified as single cases. Nevertheless some well-documented outbreaks of listeriosis have been reported from Finland [1], France [2], Switzerland [3], the United Kingdom (UK) [4] and United States (US) [5]. In Belgium, one outbreak of listeriosis has been described in 2001 [6]; data from one additional study were inconclusive [7]. In the present study, 36 clinical human strains from hospital laboratories and five food isolates were characterised by serotyping, metal resistance typing and pulsed-field gel electrophoresis (PFGE). This combination provided us with the opportunity to link strains from 11 sporadic cases.

\section{Methods}

Patients were not systematically interviewed about their food habits; clinical data were provided by clinical laboratories.

\section{Identification and molecular typing}

Since 1966, the Belgian Listeria Reference Centre (BLRC) has received hospital-isolated strains of L. monocytogenes on a voluntary basis. Strain identification is carried out with the api Listeria kit (bioMérieux, France). All strains are serotyped according to a standard protocol [8] using a commercial agglutination test (Denka Seiken, Tokyo, Japan) for somatic (0) and flagellar $(\mathrm{H})$ antigens. Strain susceptibility to arsenic and cadmium is determined according to McLauchlin et al.
[9]. Molecular typing is performed if a cluster of isolates is suspected based on geographical considerations, on the occurrence of multiple cases within a short period of time or a cluster of isolates with identical serotype.

PFGE is done following the US PulseNet protocol [10] after DNA digestion with Apal and Ascl. Analysis of the banding pattern is performed with the ImageMaster video documentation system (Amersham Pharmacia Biotech) and Fingerprinting II Informatix software (Bio-Rad). DNA extraction for Random Amplified of Polymorphic DNA (RAPD) is done with the QI Amp DNA Mini Kit; primer HLWL 74 and the PCR conditions have been described by Wernars et al. [11].

Isolation of Listeria monocytogenes from food $25 \mathrm{~g}$ of food sample were added to $225 \mathrm{ml}$ of Half Fraser broth for $24 \mathrm{~h}$ at $30^{\circ} \mathrm{C}$, followed by the inoculation of $0.1 \mathrm{ml}$ into $10 \mathrm{ml}$ of Frazer broth and incubation for $24 \mathrm{~h}$ at $37^{\circ} \mathrm{C}$. Following enrichment, $500 \mu \mathrm{l}$ of the culture was used in the VIDAS LMo2 test (bioMérieux). If positive, $10 \mu \mathrm{l}$ of the Fraser enrichment broth were subcultured on two media: RAPID L. Mono (Bio-rad) and ALOA (bioMérieux). Colonies characteristic of L. monocytogenes were further confirmed with the api Listeria kit.

\section{Results}

$B L R C$ receives annually between 30 and 68 strains of human clinical listeriosis cases, representing an annual incidence of three to six cases per million inhabitants. This incidence is comparable to the rates reported by other industrialised countries.

In 2006, 56 clinical strains were received: 19 of them were of serovar $4 \mathrm{~b}$. Monthly baseline isolations of serovar $4 \mathrm{~b}$ varied between none and two. However, in October and November 2006, five and six strains were isolated, respectively, suggesting a possible episode of listeriosis (Figure 1). These 11 isolates were first differentiated by metal resistance typing. Three metal resistance types were found: arsenic sensitive - cadmium resistant (SR) (one strain), arsenic and cadmium resistant (RR) (two strains), and arsenic and cadmium 
sensitive (SS) (eight strains). It was clear that the episodic strain was of SS phenotype.

\section{FIGURE 1}

Clinical isolates of Listeria monocytogenes serovar $4 \mathrm{~b}$ received at the Belgian Listeria Reference Centre, by month, $2006(n=19)$

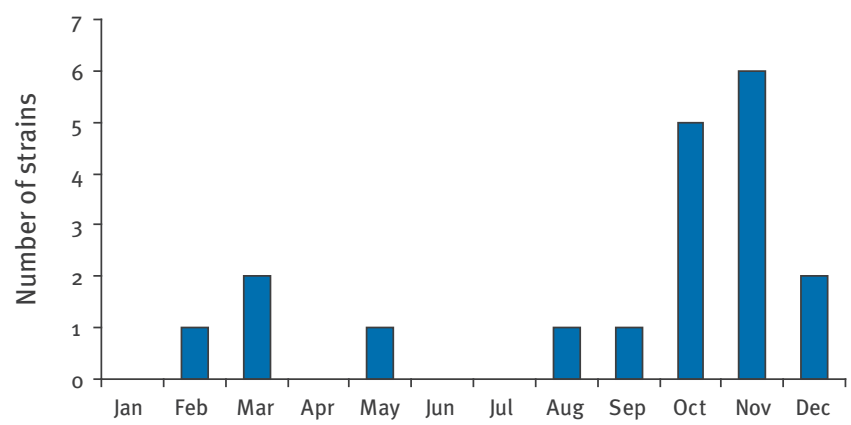

\section{FIGURE 2}

Pulsed-field gel electrophoresis AscI and ApaI profiles of Listeria monocytogenes pulsovar A

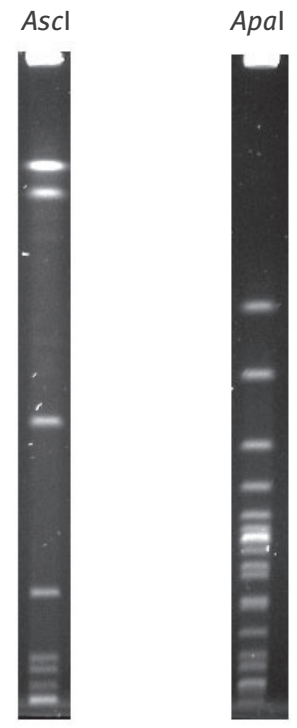

\section{FIGURE 3}

Monthly distribution of the episodic Listeria monocytogenes strain (4b,SS, pulsovar A), Belgium, October 2006-July 2007 (n=11)

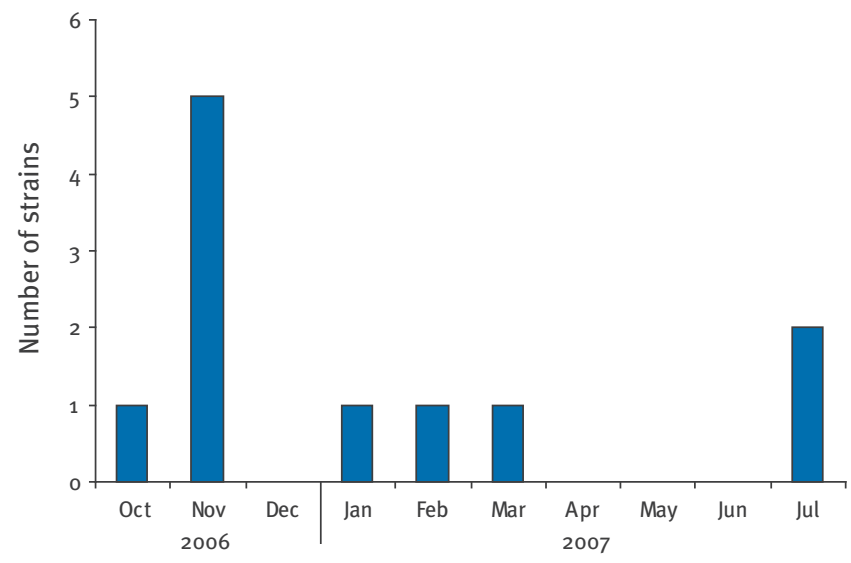

The eight strains of phenotype $4 \mathrm{~b}$ SS were further subtyped by PFGE. They belonged to three different pulsovars, with pulsovar A represented by six strains (Figure 2). The remaining two strains belonged to a different pulsovar. One of these pulsovars (B) was phylogenetic related to pulsovar $A$ with a similarity index of $92,31 \%$ (Fingerprinting II Informatix software application).

To evaluate the duration of the episode, the remaining strains of phenotype $4 \mathrm{~b}$ - SS from 2006 and those isolated in 2007 were subtyped with PFGE. Another five strains (all from 2007) were found with a profile indistinguishable from the episodic strain. The rate of isolation in 2007 was irregular: January (one strain), February (one strain), March (one strain), July (two strains) (Figure 3). The last two cases were geographically linked, indicating a local extension of the episode. Before the onset of the episode, strains with pulsovar A were very uncommon: only one strain was identified in 2005 .

A total of 11 cases appear to have been involved in this episode (six in 2006 and five in 2007). The patients' characteristics are outlined in the Table. Of the positive cultures of these patients, nine were from blood and two from cerebrospinal fluid; four cases were pregnant women or newborns. One pregnant woman had a twin stillbirth. The episode was not geographically clustered, as the isolates were received from three different regions in Belgium: Flanders, Wallonia and Brussels.

The episode was first recognised by the BLRC in November 2006. Only on four occasions were patients asked about their food habits. No standardised questionnaire was used. Suspected food samples were taken from the patients' refrigerators or from the same batch of the suspected food at the retail level. Smoked salmon was sampled because in a case of preterm birth, the mother remembered having eaten smoked salmon. Raw beef brains were the only suspected food item in a case of septicaemia. The woman with the twin stillbirth reported having eaten pre-packed lasagne; this food item was suspected after some of her housemates presented with gastroenteritis. However, L. monocytogenes could not be detected in any of these samples.

As the contamination source was not found, another line of investigation was followed. We searched the BLRC food isolations collection for a strain with the same characteristics as the episodic strain. Among the food isolates received at BLRC in 2006 and 2007, only six strains were of phenotype $4 \mathrm{~b}$-SS. They were subtyped with RAPD. Two strains isolated from poultry preparations matched the episodic strain RADP profile. However, these strains were of a different pulsovar, which excludes them from being involved in the episode. 


\section{Discussion}

In Belgium, the majority of listeriosis cases are reported as single cases. Clinical laboratories mandatorily report cases to the community health authorities. However, these authorities rarely receive information on strain characteristics, which does not facilitate linking sporadic cases. Clinical laboratories may submit their isolates to the BLRC. It is estimated that the $B L R C$ receives approximately $70 \%$ of the total number of clinical isolates in Belgium. As the BLRC performs strain typing, clusters of identical strains are easily recognised.

The combination of serotyping, metal resistance typing and PFGE led to the identification of 11 identical isolates. The episodic strain was of serovar $4 \mathrm{~b}$, sensitive to arsenic and cadmium and belonged to pulsovar $A$. Six of them were isolated within a period of a few weeks which is exceptional for a small country like Belgium. Besides the cluster isolations in 2006, the episodic strain was isolated from a further five patients in $\mathbf{2 0 0 7}$, indicating a long extension of the episode which went on until July 2007.

The source of contamination was not detected. Two factors may have contributed to this failure: no systematic interviewing of the patients and unsuccessful food sampling. During this episode only four patients were contacted by community health inspectors and only three different food samples were taken which proved to be negative for $L$. monocytogenes in $25 \mathrm{~g}$. On the other hand, the episodic strain was not present in the BLRC collection of food strains, which therefore could not provide a clue for potential suspected food items to be investigated.

Not finding the implicated food is not exceptional. In 1987, 23 cases of listeriosis in the UK were attributed to a strain of unusual serotype designated $4 \mathrm{~b}(\mathrm{X})$; the implicated food was not identified [12]. In the Netherlands, cluster analysis based on serotyping and
PFGE showed one cluster of 15 listeriosis cases without the identification of a clear source of infection [13].

Serovar $4 \mathrm{~b}$ is not unusual. In Europe and NorthAmerica, most published outbreaks of listeriosis in the past 20 years have involved $4 \mathrm{~b}$ [14]. In addition, strains of serovar $4 \mathrm{~b}$ tend to be overrepresented in perinatal listeriosis, suggesting that they may have special virulence attributes for pregnancy and breach of the bloodplacenta barrier. In the cluster described here, four of the 11 cases were pregnancy-related.

It is presumed that the episodic strain was particularly virulent because it involved a relatively high number of pregnancy-related cases and meningitis cases, four of 11 and two of 11 respectively. According to annual data from the BLRC, strains from cases with maternalneonatal listeriosis represent $10 \%$ of the total number of clinical strains; a similar proportion is observed for cases with meningitis.

It is generally accepted that persons with an underlying disease are more susceptible to contracting listeriosis. In this episode, information from only three patients was available. As it not mandatory for clinical laboratories to report to the $B L R C$, a lot of epidemiological data are ignored.

During this episode of listeriosis, we received a human Listeria strain closely related to the episodic strain. This strain was of serovar $4 \mathrm{~b}$, sensitive to arsenic and cadmium but represented another pulsovar (B). Pulsovar $B$ differs from pulsovar A by only three bands in the Apal profile. According to Tenover et al. [15], two profiles that differ by only three bands are considered as closely related. However, the similarity index between the two profiles was $92.31 \%$ and thus lower than $95 \%$, the minimum level for highly related strains. Therefore this strain was excluded from the episode.

TABLE

Patients' characteristics of the listeriosis episode, Belgium, October 2006-July 2007 (n=11)

\begin{tabular}{|c|c|c|c|c|c|c|}
\hline Isolation date & Region & Age (years) & Sex & Isolation site & Symptoms & Underlying disease \\
\hline October 2006 & Flanders & 48 & Female & Blood & Septicaemia & NA \\
\hline October 2006 & Flanders & 52 & Female & CSF & Meningitis/coma & Lupus \\
\hline November 2006 & Wallonia & 81 & Male & Blood & NA & Heart disease \\
\hline November 2006 & Wallonia & Neonate & Female & Blood & Preterm birth & NA \\
\hline November 2006 & Flanders & Neonate & Male & Blood and ear & Septicaemia/preterm birth & NA \\
\hline January 2007 & Flanders & 58 & Male & Blood & Septicaemia & NA \\
\hline February 2007 & Flanders & 36 & Female & Blood & Septicaemia/twin stillbirth & NA \\
\hline March 2007 & Flanders & Neonate & Female & Blood & Septicaemia & NA \\
\hline July 2007 & Wallonia & 59 & Male & Blood & NA & Cancer \\
\hline July 2007 & Wallonia & 54 & Female & Blood & Septicaemia & NA \\
\hline
\end{tabular}

CSF: cerebrospinal fluid; NA: not available. 
This episode would have passed unnoticed had not the BLRC performed strain typing. Efficient monitoring of listeriosis requires systematic interviewing of the patients using a standardised questionnaire. Close cooperation between community health inspectors, the Belgian Federal Agency for the Safety of the Food Chain (FASFC) and the BLRC would result in a rapid linking of sporadic cases and enhance the chance of finding the infection source in outbreaks.

\section{References}

1. Maijala R, Lyytikäinen $O$, Autio T, Aalto T, Haavisto L, Honkanen-Buzalski T. Exposure of Listeria monocytogenes within an epidemic caused by butter in Finland. Int J Food Microbiol. 2001;70(1-2):97-109.

2. de Valk H, Vaillant V, Jacquet C, Rocourt J, Le Querrec F, Stainer $\mathrm{F}$, et al. Two consecutive nationwide outbreaks of Listeriosis in France, October 1999 - February 2000. Am J Epidemiol. 2001;154(10):944-50.

3. Bille J, Blanc DS, Schmid H, Boubaker K, Baumgartner A, Siegrist $\mathrm{HH}$, et al. Outbreak of human listeriosis associated with tomme cheese in northwest Switzerland, 2005. Euro Surveill. 2006;11(6):91-3. pii=633. Available from: http://www. eurosurveillance.org/ViewArticle.aspx?Articleld=633

4. Dawson SJ, Evans MR, Willby D, Bardwell J, Chamberlain $\mathrm{N}$, Lewis DA. Listeria outbreak associated with sandwich consumption from a hospital retail shop, United Kingdom. Euro Surveill. 2006;11(6):89-91. pii=632. Available from: http:// www.eurosurveillance.org/ViewArticle.aspx?Articleld $=632$

5. Mead PS, Dunne EF, Graves L, Wiedmann M, Patrick M, Hunter $\mathrm{S}$, et al. Nationwide outbreak of listeriosis due to contaminated meat. Epidemiol Infect. 2006;134(4):744-51.

6. Doumith M, Jacquet C, Goulet V, Oggioni C, Van Loock F, Buchrieser C, et al. Use of DNA arrays for the analysis of outbreak-related strains of Listeria monocytogenes. Int J Med Microbiol. 2006;296(8):559-62.

7. Yde M, Genicot A. Use of PFGE to characterize clonal relationships among Belgian clinical isolates of Listeria monocytogenes. J Med Microbiol. 2004;53:399-402.

8. Seeliger HP, Höhne K. Serotyping of Listeria monocytogenes and related species. Methods Microbiol. 1979;13:31-49.

9. McLauchlin J, Hampton MD, Shah S, Threlfall EJ, Wieneke AA, Curtis GD. Subtyping of Listeria monocytogenes on the basis of plasmid profiles and arsenic and cadmium susceptibility. J Appl Microbiol. 1997;83(3):381-8.

10. Graves LM, Swaminathan B. PulseNet standardized protocol for subtyping Listeria monocytogenes by macrorestriction and pulsed-field gel electrophoresis. Int J Food Microbiol. 2001;65(1-2):55-62.

11. Wernars K, Boerlin P, Audurier A, Russell EG, Curtis GD, Herman L, et al. The WHO multicenter study on Listeria monocytogenes subtyping: random amplification of polymorphic DNA (RAPD). Int. J.Food Microbiol. 1996;32:325-41.

12. McLauchlin J, Crofts N, Campbell DM. A possible outbreak of listeriosis caused by an unusual strain of Listeria monocytogenes. J Infect. 1989;18(2):179-187.

13. Doorduyn Y, de Jager CM, van der Zwaluw WK, Wannet WJ, van der Ende A, Spanjaard L, et al. First results of the active surveillance of Listeria monocytogenes infections in the Netherlands reveal higher than expected incidence. Euro Surveill. 2006;11(4):E060420.4 . pii=2945. Available from: http://www.eurosurveillance.org/ViewArticle. aspx?Articleld $=2945$

14. Kathariou S. Listeria monocytogenes virulence and pathogenicity, a food safety perspective. J Food Prot. 2002;65(11):1811-29.

15. Tenover F C, Arbeit RD, Goering RV, Mickelsen PA, Murray BE, Persing $\mathrm{DH}$, et al. Interpreting chromosomal DNA restriction patterns produced by pulsed-field gel electrophoresis: criteria for bacterial strain typing. J Clin Microbiol. 1995;33(9):2233-9. 